\title{
Tour du dopage: Confessions of doping professional cyclists in a commodified work environment
}

\begin{abstract}
Despite the widespread condemnation of blood doping in sport, since Lance Armstrong's acquittal in 2012, a flurry of riders' confessions have emphasized the omnipresence and normalization of the practice within cycling. Drawing an analogy between the origins of capitalist society and sport, this paper analyses doping cyclists' confessions in the media. Whilst there are many justifications for why cyclists might dope, little is known about the reasons and processes regarding how and why individuals portray this behavior as legitimate. To show this, the study draws on concepts of neutralization theory and performance at work to introduce the notion of 'performance egoism'. Findings show how doping and 'cheating' is legitimated by cyclists operating on three levels of spectacularised work, concerning individual's performance, their team's success and the grand spectacle of the Tour de France. It is concluded that the commodification of cultural performance at work breeds an environment of legitimated cheating.
\end{abstract}

\section{Keywords}

Doping, cyclists, cheating, performance, spectacle

\section{Introduction: Understanding 'cheating' in cycling}

The commodification of sport and the vast financial expenditure devoted to it have reinforced sport's capacity as a form of spectatorship and entertainment (Furst, 1971), even though there are many accounts of the capitalist system being cheated. One example is 'drug doping' that according to Johanson (1987) has become a realistic feature of professional cycling given that 'good' performance can only be denoted by winning. 'Drug doping' pertains to performance enhancement that is commonly represented as the antithesis to sport: 'the potential to enhance or enhances the sport performance and/or presents an actual or potential health risk to the 
athlete and/or violates the spirit of the sport' (WADA, 2009: 14). Perhaps the most highprofile example illustrating this impurity came to light on the $13^{\text {th }}$ of June 2012 , when the United States Anti-Doping Agency (USADA) wrote to the seven time Tour de France (TDF) winner Lance Armstrong, charging him with conspiring in 'drug doping' between 1998 and 2011 (USADA, 2012). Since Armstrong's charge and acquittal, many more doping confessions and scandals have shown that this deemed illegitimate practice maintains prevalence among professional cyclists, despite zealous anti-doping campaigns that are costly, but yet do not eradicate the private motives for usage (Jones, 2010). These fallacies often translate to an inefficiency of testing. For example, Hermann and Henneberg (2014) have determined that to detect $100 \%$ of doping instances over a one-year period, $16-50$ tests would need to be carried out on each athlete. Perhaps unsurprisingly the prevalence of doping in cycling remains, and especially in Grand Tours. From 1996 to 2010 thirty-six out of fortyfive top three finishers in the TDF were caught doping (USADA, 2013).

As well as convincing statistics on its prevalence, discussions of doping are so overpowering that even those who have won clean - such as Chris Froome winning the TDF in 2013 - have their victory tarnished by being located in contexts that are infiltrated by moral panics and previous scandals, such as the Lance Armstrong case (Groves and Griggs, 2014). Of course, not all cyclists are dopers and as Morente-Sánchez and Zabala (2013) note, most athletes at least acknowledge the practice as cheating. In panic laden environments, high profile cyclists often deny doping through press releases and autobiographies. For example, Bradley Wiggins (2012) stated he has never doped because the risks for his family and life are too great. However, despite this denial, Wiggins' (2012) sympathizes with dopers arguing that it is not a personality issue but instead the sport's culture and peer pressure. Further ambiguity also ensues as the implications of an enforced doping ban mean it becomes difficult to garner the true extent of the problem within professional cycling because 
acknowledgement of drug use carries severe career consequences for those concerned (Jones, 2010; Pitsch and Emrich, 2012). Despite this unknown, evidence highlights that both corporization and scientization mean there are great pressures imposed on athletes to adopt any means necessary to win (Stewart and Smith, 2010). The voices of athletes who face such pressure, and who inevitably use banned substances have, however, seldom been heard (Pappa and Kennedy, 2013). There are polarized views towards doping, one-side views it as a moral indignation and the other expresses it as a necessary part of performance in top sport. The behavior of sports persons and sport as a phenomenon generally however are far from located in their own system of behavior; instead being found amongst many other multifacetted developments whose beginnings lie amongst the early-capitalist bourgeois society (Rigauer, 1981). This paper focuses on understanding how drug use and cheating is cultivated, and legitimated, by professional cyclists within the spectacle of the TDF. It begins by reviewing literature on early capitalist beliefs, framings of work performance, and cheating, before addressing the commodification of work and the sporting spectacle. Prior to outlining its methods, technique and approach towards analyzing doping cyclists' confessions, it explains it's theoretical adaptation of neutralization theory that provides a framework for understanding normalized wrongdoing. There are then three findings sections showing how and why cyclists legitimate their behavior at an individual, team and spectacle/society level, before a discussion and concluding section highlighting the contribution of 'performance egoism' at work.

\section{Early capitalist society, performance and cheating}

Early capitalist beliefs are based on a 'performative principle' historically founded on both economic alienation and repressive disiblimination. This equates to the execution of specific workplace tasks in the most efficient manner, produced by the dominant values and instrumentalities of the capitalist market, most often associated with Scientific Management 
and Taylorism. Rationalized and commodified performances then potentially become a spectacle form comprised of the structural aspects of performance that responds and adapt to market criteria. Adopting this framing of work it is clear that athletic ability can be a quantifiable commodity like any other form of social labour or performance produced by capitalist firms for profit under the conditions of market exchange (Moller, 2010). As Loland (2004) suggests, in sport, the athlete is a postmodern subject with chances to maximize their performance with whatever means they consider appropriate. This produces a competitive arena whereby individuals' objectives are not merely performing their job, but instead aiming to be 'the best that they can be'. Consequently this also produces an agenda of winning that breeds a darker side and a cult of vengeance (Alt, 1983), demonstrating much similarity with the historical trajectory of sporting behaviors in cycling.

Continuing to draw an analogy between work and sport, the recalcitrant worker or 'cheat' has been a defining theme in British sociology (Thompson and Ackroyd, 1995). Deviant or 'cheating' employees are termed 'outsiders' who impose a threat to the 'social' or 'moral' order of the company (Vardi and Weiner, 1986), but who also engage in behavior that intentionally benefits the self. Despite emphasizing the moral indignity of the employee, in literature on employee deviance it also remains evident that the way work is organized determines the form of occupational crime, deviance or cheating (Mars, 1994). This idea has become clearer more recently wherein scholars suggest that there has been a shift from a dark 'outside' that impinges upon action inside organizations, towards a dark 'inside' that is situated within the boundaries of organizations and its practice (Linstead et al., 2014). Given the revenues required for testing doping cyclists (Maennig, 2014) there is a case for understanding how these dark 'insides' are reproduced and/or how they are derived from social and cultural factors outside to organizations. 


\section{The commodification of work and the sporting spectre of cultural performance}

Since 1960 the capitalist market has transformed from one that values material goods towards a society of spectacle, resulting in more people investing time, money and energy partaking in and embracing multi-faceted phenomena such as sports (Furst, 1971). Spectacle in this sense is something visible to the eye that is large scale and impressive (Cheska, 1978) and has taken on a much more theatrical conceptualization in recent decades. One notable area of difference has been the increased emphasis of individual's embodied enactment (Mckenzie, 2001), whereby the motif becomes performative, requiring the individual to 'act out' in particular places, especially when working. With cultural performance increasing in the modern workplace, the competitive struggle remains striving for similar socially determined desirables: personal prestige and recognition (Moller, 2010). This necessitates a broader definition of performance that encompasses both what a person does, but also being an expression of what they are. Such can also be applied to athletes, and as Birrell (1981: 373) suggests: 'the athlete is now an exemplary figure who embodies the moral values of the community and thus serves as a symbol of those values'. Following this symbolism, sporting culture has been transformed from a ritualized moral order to one concerned with the production of mass spectacles (Alt, 1983), integrating individual's enacted embodied performance. Walsh and Giulianotti (2001) refer to this spectacle as part of the 'hypercommodification of sport' whereby both the quantitative value of sports have increased rapidly in addition to the secondary, non-play aspects that have become commercialized. This certainly applies with the TDF that over its 21 stages has 4700 hours of television coverage, 12 million spectators and circa 2000 reporting journalists. Subsequently, given the commodified nature of sport and work, and the spectacle that they have become, incidents of doping can no longer be meaningfully located solely within a discussion of each cyclist's inappropriate moral standing (Barthes, 1997) as doing so negates equal determinants concerned with the competitive and spectating environment in which they are located. In 
support of this there has been much research highlighting that doping is not a solitary act and that many stakeholders including professional athletes, the media, officials and team doctors all play a significant role in the definitional process (Lauber et al., 2010). However, rather than look at why cyclists dope, and the procedural institutional measures that help manifest the phenomenon, this study focuses on the strategies that individuals use to legitimate their consumption in the public arena, showing what purpose this serves for them, and the effects it has on their self-presentation of their performance whilst doing their job.

\section{Neutralization theory: Normalizing organizational wrongdoing}

The designated deviant or 'cheater' in sport and work is often framed as lacking moral awareness, knowing their behavior is 'wrong' but deciding to continue with it. However, this framing closes down in-depth understandings of how these individuals may locate their behavior within social and cultural contexts. One mechanism that can be used to overcome these concerns is the neutralization theory of Sykes and Matza (1957). This theory is applied herein and highlights the motifs and performance morals that are made explicit by professional cyclists. It does this through considering the strategies cyclists use to legitimize their doping behavior with the norm-conforming attitudes of sporting society. In particular the first three of these include a 'denial of responsibility' whereby delinquents pass on responsibility for their actions, a 'denial of injury' whereby delinquents argue that there is no harm caused by their actions, and a 'denial of victim' whereby the injury caused is not seen as wrong in light of the other person's behavior. The latter three include 'condemning of the condemners' where the delinquent blames those who disapprove of his actions, an 'appeal to higher loyalties' where more importance is placed on the delinquent's own social group rather than larger society and lastly the 'metaphor of ledger' where the benefits of the delinquent act are offset by the damaged caused. 


\section{Methods}

This study focuses on the use of the two most common performance enhancing techniques in cycling: blood-doping and Erythropoietin (EPO). The former concerns the removal, storage and re-injection of an athlete's own blood to increase the amount of oxygen that they are able to intake via an increase in red blood cells (Schjerling, 2005). The latter, EPO, is a type of growth hormone that stimulates the athlete's bone marrow to produce more red blood cells, also increasing the level of oxygen in their blood (Waddington and Smith, 2000). Owing to the difficulties in collecting primary data on doping cyclists (Ohl et al., 2013) this study analyses ad verbatim quotations from 112 cyclists' confessions in the media. Studies have already emphasized how the negativity of cycling and doping are exacerbated through the lay press who portray a damaging image of doping (Lopez, 2013). Therefore an understanding of the confession herein is one which is appropriated with Sykes and Matza's (1957) theory and which incorporates the notion that doping cyclists know their practice is perceived as cheating or impure throughout society and the cycling world. Whilst there have been debates concerning the degree of truth in confessionary statements for many decades, there is evidence that self-reported drug use is a reliable indicator of individuals' actual drug use (Mazanov et al., 2008).

Regarding access, statements have been acquired via a Google news search directed towards each cyclist, with the list of names being supplemented via two means. First, via an online database 'dopeology.org' - a database that is a topology of doping in European professional road cycling, listing all doping admission statements since 1980. Second, all names used in the United States of America Doping Agency's (USADA, 2014) case against Armstrong case were integrated. As these statements are widely available on the Internet and with the riders' real names attached, the author has not subjected these accounts to further anonymisation in the findings section. All of the cases investigated in this paper refer to professional road cycling males, as opposed to amateurs and young cyclists where doping is 
less common (Ohl et al., 2013). Males are chosen because they represent the greater sample size, and whilst the female professional cycling population is growing (British Cycling, 2014), this is still substantially disproportionate in comparison to males. To understand individuals' accounts in a non-judgmental manner, 'cheating' and 'doping' are not understood as cultural universals, but instead as modern concepts that have emerged and developed as part of broader pattern of social relationships in sport and work (Waddington and Smith, 2000). Rather than offering an apology or justification for cyclists' doping, the focus is on how their drug use within the competitive and performative arena of their work is legitimated. The agenda is therefore unpicking how doping cyclists tell their stories and the positions and understandings these demonstrate about sport and work as a mode of cultural performance.

Whilst there are an increasing range and variety of techniques available for analyzing media materials such as quantitative forms of content analysis and more qualitative forms of analysis such as discourse analysis, given the meanings and 'morals' conveyed, the approach favored a more general interpretive analysis. This approach was able to note in more detail individuals' thoughts, feelings and behaviors surrounding their doping practices. Early on in the analysis the author noted frequent disjunctions in cyclists' quotations whereby they outlined their behavior and then exemplified this with statements such as 'this was necessary because' or 'but it was impossible to compete without'. Following these justifications and the known cultural context of cycling, it was then clear that Syke's and Matza's (1957) theory would be an apt lens to apply in the analysis. The quotations were separated from the media documents and analyzed using NVivo. First they were grouped and coded into each of the neutralization strategies, they were then coded a second time to break down each strategy to a finer level. This was needed to identify the key motives for cyclists justifying their doping within each particular strategy. 


\section{Findings}

The findings of the study are now presented and show how doping cyclists suggest their drug-taking behavior is justified and legitimate to their work performance and not something they consider cheating. To do this cyclists locate their consumption as part of the production and maintenance of their performance and TDF spectacle: occurring on an individual, teambased and broader capitalist level. Considered as a whole these three instances of doping show how individuals present themselves as performative subjects who respond to the challenges of sport through legitimated cheating.

\section{Sustaining the spectacle of self}

Avoiding damage to bodies. Sykes and Matza (1957) suggest that one of the ways classified delinquents justify their behavior is through denying harm is caused to others. In the study, rather than deny that they are hurting others, cyclists took on a more self-centered role, doping to avoid damaging effects from participation in pro cycling. They also wanted to maintain the normal functioning of their bodies following heavy exertion. Their accounts drew on legitimized medical discourses, and statements often began with cyclists rejecting an identity of a doper. Instead they framed their drug use as a necessity:

\footnotetext{
'I was not a doper, I told myself - I just injected myself to recover and needed pills to sleep' (David Millar).

'In the pack you never use the word doping but medical help' (Richard Virenque).
}

By speaking of medical discourses this lead to a more individualized form of performance repatriation whereby cyclists also suggested doping was necessary to prolong and protect their own individual future performance and careers. Without these drugs cyclists would be hurt and end up with lower results when compared to non-dopers. They argued that every other cyclist neutralizes job effects by doping: 
'If you hadn't taken it you would have been slaughtered. You didn't do it to cheat. You did it to survive. To fight the battle with the same arms as everyone else' (Paul Kimmage).

Whilst cyclists' accounts emphasized equality in their chances to perform their job effectively, these narratives did not suggest that performance was 'spectacular' but rather that it was equated with mere career survival. Doping was therefore a means of maintaining cyclists' exchange value to hold their performance and job:

\footnotetext{
'It was a matter of survival, just keeping up, not getting dropped, having my place in the peloton' (Frankie Andreu).

'It felt like I'm trying to survive and there's a little raft and I can stop treading water and hoist myself up on that' (Jonathan Vaughters).
}

This highlights performance infused arrogance whereby cyclists suggest their work should not have any damaging effects on their body, despite risk and occurrence of injuries being a normalized expectation of participation in top-level sport (Albert, 1999).

Protecting careers. As well as allowing them to avoid harming their body, cyclists suggested doping was needed to prevent unnecessary physical damage on themselves, and which could impede upon their careers. They were against moving to a career that they associated with less credibility:

\footnotetext{
'My alternative would have been to drive the bicycle in the garage and stop the career' (Bo Hamburger).

'Everybody knew that the whole peloton was taking drugs and I had a choice. Either I buckle and go with the trend or I pack it in and go back to my old job as painter' (Alex Zulle).
}

Cyclists' conceptualized their self-understanding through a fear of failure and a vision of an idealized self that links the present to the future, and the future to the past (Schmitt and Leonard, 1986). Also, clearly whilst venalisation, where the pursuit of money becomes the modus operandi for action is at stake here, what also seems important is a collective memory 
that is public and shareable, containing episodes of success and failure. It is not the acquisition of the most financial capital that matters to cyclists but instead their public identity. Furthermore the performative identity of being a successful cyclist carries little exchange value in the capitalist market once the cyclist ends their sporting career, even though the intrinsic value of being a cyclist is hard for individuals to forget.

Appealing to career loyalties. The consequences of suggesting their doping is justified to avoid self-injury on both a physical and career progression level was that it enabled cyclists to appeal to higher loyalties in their statements. Syke's and Matza (1957) argue delinquents justify their behavior by suggesting they sacrifice the demands of the larger society, choosing instead to favor their own social groups. This justification was also similarly represented with the cyclists' accounts, however, whereas Syke's and Matza (1957) suggest individuals attended to group level needs in their justifications, cyclists instead provided more selfcentered justifications pertaining to their own self-esteem in society. Here they presented their job as an eternally dreamed of profession:

\footnotetext{
I was closest to my dream than I had ever been so I never stopped to think because I had already justified it in my mind and I had already accepted it (Floyd Landis).

Cycling has always been a part of my life. As a boy my dream was to become a professional cyclists who raced at the highest level in Europe (Michael Barry).
}

Cyclists' accounts emphasised a personal right to achieve their dream and which they could only achieve if they doped. Whilst dreaming of success, and perceiving one's aspirations on a visionary level are often requisite for realizing actual performance in sport (see Morris et al., 2005) cyclists used this as a mechanism for justifying continual doping. They built on their dreams by placing their job performance as the pinnacle tantamount to their life-world and 
existence. It allowed them to suggest that any alternative career; or social existence will always be secondary class to them:

'I started this point with the greatest dreams in the world, because I set myself a goal and I wanted to work or win money or to be someone' (Jesus Manzano).

'Cycling is my life and has been ever since I can remember. I have loved and lived this sport but more than a decade ago, I chose the wrong path' (Ryder Hesjedal).

There is an implicit assumption within accounts that cycling is like other normalized professions whereby each individual has the same chance of success in their role and should not be denied this opportunity. Cyclists therefore articulated reward as being commensurate with effort and believe they have a right to this reward, provided they put in their perception of the required amount of effort.

Team spectacle and 'badge of honor'

Fulfilling team expectations. Whilst cyclists' accounts justified their doping as a way of maintaining and incorporating a spectacle of performance to the self, they also demonstrated how this spectacle to self was a necessary part of the normal functioning of their teams. There was a performative element to their drug use whereby there was value in showing to other team mates that they were prepared to risk taking drugs to support the team's overall performance. Syke's and Matza (1957) suggest that even if delinquents accept their responsibility for their deviant actions hurting others, people attempt to neutralize this moral indignation by insisting that the injury cannot be defined as wrong within the broader environment. As with the strategy of denying self-injury, cyclists here also presented a selfregulatory and commodified position of themselves, as opposed to considering the effects that their actions might have on other riders. It was clear from their accounts that they felt there was an expectation within the team that they would dope to perform at their best. 
Cyclists justified this out of necessity by highlighting that doping was an important part of being allowed to do the job. Not taking this risk would mean they were seen as abnormal counterproductive citizens to the performative team culture and would not be allowed to race. The uncertainty and manner of this risk-taking also reinforces the spectacle whereby this willingness for risk becomes an important part of team level spectacle performance. On one level doping was presented as necessary to be accepted, or allowed to race in the team:

\footnotetext{
It became obvious that if I wanted to stay competitive and be selected to do all the big races, I had to participate in a team-doping program (Stephen Hodge).
}

Because of my career and the team I ended-up on, if I wasn't willing to do that (dope), I wasn't going to be there (Floyd Landis).

Beyond this, there was also an additional performative narrative in cyclists' accounts whereby being seen to be performing the risks of doping was necessary to maintain an acceptance by fellow team members:

\footnotetext{
One speed bag later, I was back in the safe zone. It's a team sport (Tyler Hamilton).

The pressure not to let myself and my team down saw to it that I took refuge in EPO (Tom Lotz).
}

Therefore the spectacle also operates at the level of teams and provides an arena for cyclist's to justify their cheating within. Here it is the visualized process of doping that is commodified in the performance of the act itself, as opposed to the potential effects of doping on a cyclist's performance. This suggests that doping is a 'cultural' symbol expressing an 'ideology' of performative risk that sustains the overall dominant performative team culture. Such presents a different view to the frequent perception of immoral characters as narcissists (e.g. Raskin and Hall, 1979) because here cyclists outwardly behave in ways that support the team and its members. 
Negligence of the cycling 'system'. Whilst riders justified their doping by suggesting they had to be seen to be taking drugs within their teams, they continued to shift responsibility for drug taking by blaming the cycling 'system' that is infiltrated with capitalist motives. In particular, cyclists discussed the disposable nature of their career as a result of the capitalist spectacle:

\begin{abstract}
Why haven't they made every possible effort to eliminate this cancer? It's as if the riders are entirely disposable, wheel them in for the show and then discard them. It's time to put a stop to the massacre...I was disgusted....I blamed the system. The race organisers, the directeurs sportifs, the sponsors - the men in power who knew what was going on but turned a blind eye to it. And when his career ended the system would spit him out as a penniless ex-pro (Paul Kimmage).
\end{abstract}

Leading on from their dissatisfaction for the cycling 'system', cyclists also suggested they should have been told to stop doping by the 'system' and team management hierarchy. As this act of paternalism had not materialised, they therefore suggested it was legitimate for them to carry on with their performance enhancement:

\footnotetext{
There was no dissenting voice. Doping was a way of life and a way of riding. It was easy to be influenced, doping was widespread. They should have told me to be patient and to stay clear of doping, but that wasn't the case (Thomas Dekker).
}

Since we are constantly asked to go faster and to make even greater efforts, we have no choice but to take stimulants (Jacques Anquetil).

Whilst this does actually show narcissistic tones as a result of blaming others, cyclists are alluding to a spectacle on a team level whereby the team managers are subject to the same performative requirements as cyclists themselves. The overall pressure of the TDF therefore infiltrates down the cycling managerial hierarchies and as a way of overcoming this, individuals drew on egoistic tones of their own ideological position of selves to demonstrate how doping becomes legitimated at the team level. 


\section{Spectacle and spectatorship of cycling grand tours}

Performing Tour exceptionality. The final level on which doping was framed in cyclists' accounts was at the broader level of the spectacle in society and spectatorship. As well as shifting responsibility for their doping and cheating onto the team culture and cycling 'system' infiltrated by capitalism, cyclists also justified their doping by blaming the exceptional measures required by grand spectacles such as the TDF, using this to take responsibility off themselves. The cyclists presented doping as behavior they are compelled to engage in because of the competitive environment in which they work in:

\footnotetext{
But without EPO you can ride only ten stages at a very high level. Afterwards the fire is out (Rolf Jarmann).

In cycling, you get dropped in 99 out of 100 races, even when you give it everything. It hurts all the time; but you still are successful only a few times (Jorg Jaksche).
}

Another key way that cyclists legitimated their doping at this level was to blame the landscape and terrain of the Tour that places exceptional requirements on their body, and which could not be accomplished without doping. Cyclists' highlighted that the level of performance required was impossible to achieve without performance enhancement:

\footnotetext{
Well it's hard to imagine the endurance demanded by the Tour de France 21 days, 2000 miles and a vicious vertical climb totalling some 50,000 feet in all. This ordeal is one reason that cycling became a dirty sport (Tyler Hamilton).
}

Doping as framed in cyclists' accounts therefore is represented as the material object that transpires their performance into a commodity and that in turn carries an exchange value enabling them to achieve tour exceptionality. By attributing blame to the Tour landscape and terrain it allows cyclists to uphold their own position and ego of seeing their performance as successful from their own perception. A second way that riders denied responsibility was by presenting the Tour as an impossible task that could not be completed without doping: 
My experiences during that first week made me question whether it was even possible to compete in a race like that without doping (Michael Barry).

You don't understand, this is the only was I can even finish the Tour (Frankie Andreu).

The Tour de France was no ordinary race. It made superhuman demands on the human body. Riding six hours a day for twenty-three days was not possible without vitamin supplements, mineral supplements, chemicals to clean out a tired liver, medication to take the hardness out of rock-hard leg muscle (Paul Kimmage).

Balancing the effort and reward ledger. Syke's and Matza (1957) use the metaphor of the ledger where acceptable behavior is perceived by the delinquent as an accrual of credits that are traded to frame their cheating behavior as legitimate. This operated by individuals suggesting their doping was legitimate due to the level of performance and effort that they had to put in. They thought this effort was very high and therefore warranted doping. Here they focused on the many sacrifices that they have made, including their long hours training and strict diet:

I felt that I had been putting in a great deal of work, but not getting the results that I should have been able to achieve. Lance told me that he would contact Dr. Ferrari on my behalf' (George Hincapie).

'We speak a lot about doping when we speak about cycling. But don't often speak about the hours of training or about the sacrifices that most cyclists make' (Fabien Tallefer).

'Cycling per se is not fun. It always hurts. The sport is a lot about pain, physical pain’ (Jorg Jaksche).

Cyclists use their intrinsic effort as an exchangeable commodity that enables them to engage in doping. As well as suggesting the more materialized sacrifices, cyclists also suggested they were legitimated to dope due to the many years that they have had to sustain their effort over. The consequences of presenting their performance in this way shows how cyclists self-brand and commodify their performance as a means of overcoming the difficulties encompassed in performing for the spectacle and which they articulate as being above the normal call of duty. 
Emphasizing their performance in this quantifiable manner therefore is a means through which cyclists search for an authentic self at work (Hoberman, 2000).

\section{Discussion and conclusion: Performance egoism in sport and work}

This paper has shown that in professional cycling the nature of the spectacle defined cultural performance drives individuals' legitimate goal seeking through the illegitimate means of doping. In agreement with Walsh and Giulianotti (2001), the commodification of cycling appears to bring with it a radical overthrow of prior social, economic, political and cultural arrangements in the service of maximizing profit and in response to the wider cultural aspects of competition and work. The findings lead to three more specific conclusions concerning the consequential effects of the commodification of cycling.

First, despite using means that are often perceived illegitimate by key stakeholders, the cyclists engaged in a process of self-commodification that enabled them to appropriate an identity that they understand as being fundamentally existent in the successful cyclist or employee (Dale, 2012), and certainly not one that 'cheats'. Throughout the study, this lead to the development of a 'performance ego' on three levels and which allowed cyclists to defend the legitimacy of their cheating. First, this occurred at the individual level whereby cyclists suggested they engaged in doping practices to avoid damage to their bodies. Here their ego was at play whereby they wanted to show to themselves that they could continue to perform their ideal career. Second, cyclists suggested their doping was necessary to show that their performance was adequate to their fellow teammates, but also to show that they were willing to take risks to perform at their best for the team. Their egos came into play here whereby their cheating was a means to show how serious they were with regard to producing the best possible performance for the team. Third, cyclists emphasized the spectacular exertion required by the Tour and doing so allowed them to protect their performance egos by suggesting that what they were engaging in was beyond the 'normal' parameters of the 
human body. In this sense they represented their doping as a tool that enabled them to perform beyond the 'normal' and to continue to perform spectacularly within the Tour spectacle.

Second, in the same way that an analogy can be drawn work to sport, it can also be drawn from sport to work in a modern era of elitism and exceptionality. The findings of the study have shown how achievement, performance and success have become an ideology that are rendered as integral to individuals' success, regardless of the style or moral arena in which this is achieved. As Motion (2000) argues, image management can be considered as a productive process, whereas impression management is more performative. In this sense cyclists are more concerned with the overall impression they give, instead of the means in which this is produced. Therefore, ultimately the findings have paved the way for more indepth study of the mechanisms and strategies that are used in sport in contextualized areas of elitism and exceptionality. This carries further resonance for understanding how high impact scandals in sport and athletic teams continue to place increasing pressure on organizations, communities and governments to manage athletes' behavior in ways that are non-detrimental to the financial and social performance of sport in the contemporary economy. This is further important given that prolonged research suggests that most adults' decision making is highly susceptible to the external environment in which they are located, making the management of cultural norms imperative (Trevino et al., 2006). If the more performative and subjective elements of performance are measured, as opposed to the productive and quantitative means, this opens a large ontological lacuna requiring debate of the nature and measurement of success in sport.

Third, it is also important to think about the reflexive agendas used by these cyclists. Broadly their accounts highlight the self-imposed value attached to the importance of reflexivity and self-presentation in modern times (Giddens, 1971). Whilst there are elements 
of a narcissistic tone echoed throughout, as cyclists do not call into question their own performance and do not hold themselves accountable, implicitly these cyclists must ultimately have a reason for sharing this self-knowledge in the public domain. Personal branding is ever prominent (Wee and Brooks, 2010) and therefore it is hard to fathom, given the narcissistic tone and personalities demonstrated that cyclists do not attach some value to this process, whether that be for the benefit of themselves or others. Supporting this, as Cluley and Dunne (2012) note, at the moment of consumption consumers may be faced with an 'as if' moment whereby they realize that their decision may not have been the best possible choice. Consequently many continue to consume what their aspirations attract them to, as if they did not know the uncomfortable facts about the production process. Therefore whilst one limitation of the study might be that too much weight has been placed onto individuals' accounts, a common criticism of self promotion (e.g. company reports (Koller, 2008)), the fact that athletes and individuals feel the need to publicise a bolstered self-identity highlights the modern sporting and working environment whereby self promotion is tantamount to fulfilling the ever performative nature of being seen as ubiquitously successful in the job.

\section{References}

Albert E (1999) Dealing with danger; the normalization of risk in cycling. International Review for the Sociology of Sport 34: 157-171.

Alt J (1983) Sport and cultural reification: from ritual to mass consumption. Theory, Culture and Society 1: 93-107.

Barthes R (1997) The Eiffel tower and other mythologies. University of California Press: California.

Birrell S (1981) Sport as ritual: interpretations from Durkheim to Goffman. Social Forces 60: 354-376.

British Cycling (2014) A journey of inspiration and opportunity: Our vision for women's cycling. British Cycling: Manchester.

Cheska A (1978) Sports spectacular: a ritual model of power. International Review for the Sociology of Sport 14: 51-72.

Cluley R and Dunne S (2012) From commodity fetishism to commodity narcissism. Marketing Theory 12: 251-265.

Dale K (2012) The employee as 'dish of the day': The ethics of the consuming/consumed self 
in human resource management. Journal of Business Ethics 111: 13-24.

Furst R (1971) Social change and the commercialization of professional sports. International Review for the Sociology of Sport 6: 153-173.

Giddens A (1971) Modernity and self-identity: Self and society in the late modern age. Polity: Cambridge.

Groves M and Griggs G (2014) Riding in the shadows: The reaction of the British print media to Chris Froome's victory in the 2013 Tour de France, International Review for the Sociology of Sport DOI: 1012690214534848.

Hermann A and Henneberg M (2014) Anti-doping systems in sports are doomed to fail: A probability and cost analysis. Available at: http://road.cc/content/news/89328-antidoping-systems-sport-doomed-fail-says-study (accessed 15th August 2014).

Hoberman J (2000) Testosterone dreams; Rejuvenation, aphrodisiac, doping. University of California Press: California.

Johanson M (1987) Doping as a threat against sport and society: The case of Sweden. International Review for the Sociology of Sport 22: 83-97.

Jones C (2010) Doping in cycling: Realism, antirealism, and ethical deliberation. Journal of the Philosophy of Sport 37: 88-101.

Koller V (2008) Identity, image, impression: Corporate self-promotion and public reactions. In: Wodak R Koller V (eds.) Handbook of communication in the public sphere. Berlin: Walter de Gruyter: 155-180.

Lauber M Jamieson K and Krohn M (2010) Newspaper reporting and the production of deviance: Drug use among professional athletes. Deviant Behaviour 14: 317-339.

Linstead S Marechal G and Griffin R (2014) Theorizing and researching the dark side of organizations. Organization Studies 35: 165-188.

Loland S (2004) Normative theories of sport: A critical review. Journal of the Philosophy of Sport 31: 111-121.

Lopez B (2013) Creating fear: The social construction of human growth hormone as a dangerous doping drug. International Review for the Sociology of Sport 48: 220-237.

Maennig W (2014) Inefficiency of the anti-doping system: Cost reduction proposals. Substance Use and Misuse 49: 1201-1205.

McKenzie J (2001) Perform or else: From discipline to performance. Routledge: London.

Mars G (1994) Cheats at work: Anthropology of workplace crime. Allen \& Unwin: Aldershot.

Mazanov J Petroczi A Bingham J and Holloway A (2008) Towards an empirical model of performance enhancement supplement use. Journal of Science and Medicine in Sport 11: 185-190.

Moller V (2010) The ethics of doping and anti-doping: redeeming the soul of sport. Routledge: London.

Morente-Sánchez J and Zabala M (2013) Doping in sport: a review of elite athlete's attitudes, beliefs and knowledge. Sports Medicine 43: 395-411.

Morris T Spittle M and Watt A (2005) Imagery in sport. Human Kinetics: Leeds.

Motion J (2000) Personal public relations: Identity as a public relations commodity. Public Relations Review 25: 465-479.

Ohl F Fincoeur B Lentillon-Kaestner V Defrance J and Brissonneau C (2013) The socialization of young cyclists and the culture of doping. International Review for the Sociology of Sport DOI:1012690213495534.

Pappa E and Kennedy E (2013) 'It was my thought... he made it a reality'. International Review for the Sociology of Sport 48: 277-294.

Pitsch W and Emrich E (2012) The frequency of doping in elite sport: Results of a replication study. International Review for the Sociology of Sport 47: 559-580. 
Raskin R and Hall C (1979) A narcissistic personality inventory. Psychological Reports 45: 590-590.

Rigauer B (1981) Sport and work, Columbia University Press: New York.

Schjerling P (2005) The basics of gene doping In: Tamburrini C and Tännsjö T (eds.) Genetic technology and sport: ethical questions. Routledge: London.

Schmitt R and Leonard W (1986) Immortalizing the self through sport. American Journal of Sociology 91: 1088-1111.

Stewart B and Smith A (2010) The role of ideology in shaping drug use regulation in Australian sport. International Review for the Sociology of Sport 45: 187-198.

Sykes G and Matza D (1957) Techniques of neutralization: A theory of delinquency. American Sociological Review 22: 664-670.

Thompson P and Ackroyd S (1995) All quiet on the workplace front? A critique of recent trends in British Industrial Sociology. Sociology 29: 615-633.

Trevino L Weaver G and Reynolds S (2006) Behavioural ethics in organizations: A review. Journal of Management 32: 951-990.

USADA (2013) Report on proceedings under the World anti-doping code and the USADA protocol. Available at: http://d3epuodzu3wuis.cloudfront.net/ReasonedDecision.pdf (accessed 2nd November 2014).

Vardi Y and Wiener Y (1996) Misbehaviour in organizations: A motivational framework. Organization Science 7: 151-165.

WADA (2009) World Anti-Doping Code 2009. Available at: https://www.wada-ama.org/en/resources/the-code/world-anti-doping-code-2009\#.U5Rpqi7n9s (accessed 15th August 2014).

Waddington I and Smith A (2000) Sport, health and drugs: A critical sociological perspective. Routledge: London.

Walsh A and Giulianotti R (2001) This sporting mammon: A normative critique of the commodification of sport. Journal of the Philosophy of Sport 28: 53-77.

Wee L and Brooks A (2010) Personal branding and the commodification of reflexivity. Cultural Sociology 4: 45-62.

Wiggins B (2012) My time: An autobiography. Yellow Jersey Cycling Classics: London. 